\title{
Enterococcus faecium NCIMB 10415 administration improves the intestinal health and immunity in neonatal piglets infected by enterotoxigenic Escherichia coli K88
}

Xie Peng ${ }^{1 \dagger}$, Ru Wang ${ }^{1 \dagger}$, Liang Hu', Qiang Zhou', Yang Liu', Min Yang ${ }^{1,2}$, Zhengfeng Fang ${ }^{1}$, Yan Lin', Shengyu Xu', Bin Feng ${ }^{1}$, Jian $\mathrm{Li}^{1}$, Xuemei Jiang ${ }^{1}$, Yong Zhuo ${ }^{1}, \mathrm{Hua} \mathrm{Li}^{1}$, De Wu ${ }^{1 *}$ and Lianqiang Che ${ }^{1^{*}}$ (D)

\begin{abstract}
Background: This study aimed to investigate the effects of oral administration of Enterococcus faecium NCIMB 10415 (E. faecium) on intestinal development, immunological parameters and gut microbiota of neonatal piglets challenged with enterotoxigenic Escherichia coli K88 (ETEC). A total of 96 1-day-old sow-reared piglets were randomly assigned to 2 groups, with 48 piglets in each group. The piglets were from 16 litters (6 piglets each litter), and 3 piglets each litter were allocated to the E. faecium-supplemented (PRO) group, while the other 3 piglets were allocated to the control (CON) group. After colostrum intake, piglets in the PRO group were orally administrated with $3 \times 10^{9} \mathrm{CFU}$ E. faecium per day for a period of one week. On day 8, one piglet per litter from each group was challenged (CON+ETEC, PRO+ETEC) or not (CON-ETEC, PRO-ETEC) with ETEC in a $2 \times 2$ factorial arrangement of treatments. On day 10 (2 days after challenge), blood and tissue samples were obtained from piglets.

Results: Before ETEC challenge, there were no significant differences for the average daily gain (ADG) and fecal score between the two groups of piglets. After ETEC challenge, the challenged piglets had greater fecal score compared to the non-challenged piglets, whereas E. faecium administration was able to decrease the fecal score. Piglets challenged with ETEC had shorter villous height, deeper crypt depth, and reduced number of goblet cells in the jejunum and decreased mRNA abundance of claudin-1 in the ileum, whereas increased the percentage of lymphocytes, concentrations of IL-1 $\beta$ in the plasma and TNF-a in the ileal mucosa, as well as increased the mRNA abundances of innate immunity-related genes in the ileum tissue. These deleterious effects caused by ETEC were partly alleviated by feeding E. faecium. In addition, piglets in PRO-ETEC group had decreased the percentage of CD8 ${ }^{+} \mathrm{T}$ cells of the peripheral blood when compared to those in CON-ETEC group. Moreover, E. faecium administration increased Verrucomicrobia at phylum level and decreased Bilophila at genus level.

(Continued on next page)
\end{abstract}

\footnotetext{
*Correspondence: wude@sicau.edu.cn; clianqiang@hotmail.com

${ }^{+}$Xie Peng and Ru Wang contributed equally to this work.

'Key Laboratory for Animal Disease-Resistant Nutrition of the Ministry of

Education of China, Institute of Animal Nutrition, Sichuan Agricultural

University, Chengdu, Sichuan 611130, People's Republic of China

Full list of author information is available at the end of the article
}

(c) The Author(s). 2019 Open Access This article is distributed under the terms of the Creative Commons Attribution 4.0 International License (http://creativecommons.org/licenses/by/4.0/), which permits unrestricted use, distribution, and reproduction in any medium, provided you give appropriate credit to the original author(s) and the source, provide a link to the Creative Commons license, and indicate if changes were made. The Creative Commons Public Domain Dedication waiver (http://creativecommons.org/publicdomain/zero/1.0/) applies to the data made available in this article, unless otherwise stated. 
(Continued from previous page)

Conclusions: These results suggest that oral administration of E. faecium alleviated the intestinal injury and diarrhea severity of neonatal piglets challenged by ETEC, partly through improving the intestinal microbiota and immune response. This offers a potential strategy of dietary intervention against intestinal impairment by ETEC in neonatal piglets.

Keywords: Enterococcus faecium, Enterotoxigenic Escherichia coli K88, Gut microbiota, Immunity, Intestine, Neonatal piglets

\section{Background}

The gastrointestinal tract of neonatal piglets is vulnerable to diarrhea during the early-life period [1]. Before birth, the intestinal tract of fetus has been assumed to be sterile, while the newborns have been colonized by a complicated community of microbiota [2-4]. Dysregulation or imbalance of the neonatal gut microbiota may lead to higher risk of diseases and long-term negative effects on host health [5]. Increasing evidences showed that early microbiota colonization could affect the microbial composition and immunological maturation $[6,7]$. Thus, early colonization with beneficial bacteria resulting in the establishment of a stable bacterial ecology may have practical significance to improve the health of neonatal piglets.

Neonatal piglets are often infected with pathogenic bacteria derived from either maternal or environmental source [8]. The infection of ETEC K88 is one of the important causes for diarrhea of neonatal and post-weaning piglets, resulting in lower growth rate and great economic loss in the pig farming [9]. Severity of diarrhea can be up to $50 \%$ in suckling piglets [10]. ETEC produces enterotoxins that disturb the gut microbiota and stimulate the loss of water and electrolytes, leading to diarrhea [11, 12]. Numerous studies have showed that probiotics can inhibit the growth of potential pathogens and prevent diarrhea in pigs [13-15]. Enterococcus faecium (E. faecium) is one of lactic acid bacteria with inhibitory effects against several important enteric pathogens [16]. It has been demonstrated that oral administration of E. faecium from birth to weaning had the potency to reduce the diarrhea severity [17]. In addition, E. faecium was previously used to improve intestinal microbial balance of pigs $[18,19]$, modulate the composition of blood lymphocytes [20], and regulate the immunological homeostasis in the intestine [21, 22]. However, under ETEC challenge, the effects of oral administration of E. faecium on diarrhea severity, intestinal microbial community structure and immunological parameters in neonatal piglets have rarely been reported.

Therefore, the aim of this study was to determine the hypothesis that oral administration of E. faecium could improve the negative effects of ETEC infection on intestinal function, microbiota and immune responses of neonatal piglets.

\section{Materials and methods}

Animals, diets and treatments

All experimental procedures followed the current law regarding animal protection (Ethic Approval Code: SCAUAC201308-2) and were approved by the Guide for the Care and Use of Laboratory Animals prepared by the Animal Care and Use Committee of Sichuan Agricultural University. Sixteen litters of newborn piglets (10 11 piglets in each litter), derived from sixteen sows with the similar parities (parity 3 4). All the piglets were delivered vaginally at the Giastar Pig Experimental base (Duroc $x$ Landrace $\times$ Yorkshire) and allowed the consumption of colostrum for $24 \mathrm{~h}$. Afterwards, a total of 96 piglets (6 piglets each litter) with an initial BW of $1.72 \mathrm{~kg}$ (SEM 0.05) were selected, and 3 piglets each litter were allocated to the PRO group, while the other 3 piglets were allocated to the control $(\mathrm{CON})$ group. All the piglets were sow-reared. Piglets in the PRO group were orally administered $3 \times 10^{9}$ CFU Enterococcus faecium NCIMB 10415 per day, dissolved in $9 \mathrm{~mL}$ of physiological saline and $3 \mathrm{~mL}$ of solution was given by using a $10 \mathrm{~mL}$ syringe without the needle at 08:00, 14:00 and 20:00 h. The counts of viable probiotic bacteria in the E. faecium-containing supplements were verified via cultural method using a selective medium [23]. Piglets in the CON group were orally administered with the same volume of physiological saline. No antibiotics were given to the animals throughout the trial for prophylactic or therapeutic reasons. The oral administration lasted 7 days from the age of 2 to 8 days. One week after administration, the body weight was measured and average daily weight gain (ADG) was calculated $[24,25]$. The fecal scores were recorded according to the following criteria: 0, normal; 1, pasty; 2, semiliquid; and 3, liquid [26].

At $08: 00 \mathrm{~h}$ on day 8 , one healthy male piglet with $\mathrm{BW}$ closest to the average BW of each litter was selected from each group $(n=16)$. Piglets were checked daily for clinical signs (i.e., diarrhea, dehydration, and apathy) to evaluate their health status before challenging with ETEC. Eight of piglets in each group were orally administered with $80 \mathrm{~mL}$ of sterilised Luria broth as the 
unchallenged group, while another 8 piglets were administered with an equivalent amount of Luria Broth containing $10^{9} \mathrm{CFU} / \mathrm{mL}$ ETEC (serotype O149:K91:K88ac; China Veterinary Culture Collection Center) as the challenge group, as previously reported [27]. Therefore, four groups of piglets were created and studied: CON-ETEC; CON+ETEC; PRO-ETEC; PRO+ETEC $(n=8)$. The experimental design is detailed in Additional file 1: Figure S1. To prevent cross-contamination between groups, high hygienic standards were maintained at all times, including the change of disposable boots, coverall and gloves between rooms, and the unchallenged and ETECchallenged piglets were housed in their respective nursing cages $(0.8 \mathrm{~m} \times 0.7 \mathrm{~m} \times 0.4 \mathrm{~m})$ by separate sanitary rooms. Room temperature was maintained at approximately $30^{\circ} \mathrm{C}$, and the humidity was controlled between $50 \%$ and $60 \%$ [28].

The fecal scores were recorded at 4, 8, 12, 16, 20 and $24 \mathrm{~h}$ after ETEC challenge. During the challenge study, piglets were bottle-fed individually with formula milk every $3 \mathrm{~h}$ between 06:00 and 24:00 daily. The formula milk was formulated according to our previous study [29]. The liquid formula milk was prepared by mixing 1 $\mathrm{kg}$ of formula powder (DM 87.5\%) with $4 \mathrm{~L}$ of water, in which nutrients composition and levels were similar as sow milk [30]. All piglets had free access to drinking water.

\section{Bacterial strain}

The ETEC K88 strain (serotype O149:K91:K88 ac; China Veterinary Culture Collection Center) was grown in Luria broth medium containing 1\% tryptone, $0.5 \%$ yeast extract, and $1 \% \mathrm{NaCl}, \mathrm{pH} 7.0$. Tryptone and yeast extract were from Oxoid (Basingstoke, England). After overnight incubation at $37{ }^{\circ} \mathrm{C}$ with shaking, bacteria were diluted 1:100 in fresh Luria broth. Following incubation, the bacterial cells were harvested by centrifugation at $3,000 \times g$ for $10 \mathrm{~min}$ at $4{ }^{\circ} \mathrm{C}$, washed in sterile physiological saline, and resuspended in saline. Bacteria grown to mid-log phase (about 0.5 OD600) were used for the challenge experiment. Bacterial concentration was determined by densitometry and confirmed by serial dilution followed by viable plate counts on Luria broth agar.

\section{Blood sampling}

At 08:00 $\mathrm{h}$ after 2 days of ETEC challenge, blood samples were collected from the anterior vena cava after an overnight fast. Blood samples of $2 \mathrm{~mL}$ were injected into Eppendorf tubes containing sodium heparin for the examination of routine blood and flow cytometry analysis within $2 \mathrm{~h}$ after collection. Blood samples of $8 \mathrm{~mL}$ were contained in heparinized tubes, followed by 3 ,
$000 \times g$ at $4{ }^{\circ} \mathrm{C}$ for $15 \mathrm{~min}$, plasma was separated and then immediately stored at $-80^{\circ} \mathrm{C}$ for later analysis.

\section{Tissue sample collection}

After blood sampling on day 10 (2 days after challenge), piglets in the ETEC challenge study $(n=8)$ were sedated with an intravenous injection of pentobarbital sodium $(10 \mathrm{mg} / \mathrm{kg} \mathrm{BW})$ and euthanized with an intramuscular injection of pentobarbital sodium $(15 \mathrm{mg} / \mathrm{kg} \quad \mathrm{BW})$ followed by a subsequent exsanguination protocol approved by the Sichuan Agricultural University Animal Care Advisory Committee. After the abdomen was exposed, jejunal sample of approximately $2 \mathrm{~cm}$ in length was stored in $4 \%$ paraformaldehyde solution for histological measurements. Ileal segments $(6 \mathrm{~cm}$ in length) were opened longitudinally, and washed with ice-cold PBS to remove digesta. Mucosa was gently scraped with a sterile glass microscope slide at $4^{\circ} \mathrm{C}$, rapidly frozen in liquid $\mathrm{N}_{2}$ and stored at $-80^{\circ} \mathrm{C}$ for further analysis of inflammatory cytokines. Another ileum ( $2 \mathrm{~cm}$ in length) tissue samples were collected, snap-frozen and stored at $-80^{\circ} \mathrm{C}$ for the analysis of mRNA expression. Approximately $10 \mathrm{~g}$ of colonic digesta from each piglet was dispensed into two sterilized $5-\mathrm{mL}$ centrifuge tubes, and immediately frozen at $-80^{\circ} \mathrm{C}$ for later analysis of bacterial $16 \mathrm{~S}$ rRNA and short chain fatty acids (SCFAs).

\section{Routine blood examination and lymphocyte subtype analysis}

Routine blood examination included lymphocytes, neutrophils, intermediate cells, red blood cells, haematocrit, mean corpuscular volume, platelets, thrombocytocrit, and white blood cells. These parameters were analyzed using an automatic blood analyzer (Advia 120, Bayer HealthCare, Tarrytown, NY). Lymphocyte subtype was measured by a FACS Calibur flow cytometer (Becton, Dickinson and Company, San Jose, CA). Briefly, mouse anti-porcine $\mathrm{CD} 3$, mouse anti-porcine $\mathrm{CD} 4$, and mouse anti-porcine CD8 (Southern Biotechnology Associates, Birmingham, AL, USA) were added into $100 \mu \mathrm{L}$ of blood in a $12 \mathrm{~mm} \times 75 \mathrm{~mm}$ tube. The tube was gently mixed and incubated for $30 \mathrm{~min}$ in the dark at room temperature, then added $1 \mathrm{~mL}$ of $\mathrm{RBC}$ lysing solution (BD Biosciences, USA) and incubated for another 10 min. The cocktail was centrifuged at $500 \times g$ for $5 \mathrm{~min}$, then re-suspended with PBS and detected by flow cytometer. The percentage of $\mathrm{CD}^{+}, \mathrm{CD}^{+}$, and $\mathrm{CD}^{+}$lymphocytes were determined by CellQuest software program (BD Biosciences, USA).

\section{Plasma and ileal cytokines analysis}

Before measurement, approximately $0.1 \mathrm{~g}$ of frozen ileal mucosa was homogenized in 10 volumes $(1: 10, w / v)$ of ice-cold physiological saline by using ultrasonic cell 
disruption system (Scientz-IID, Scientz, Ningbo, China) at $4{ }^{\circ} \mathrm{C}$, and then centrifuged at $4,500 \times g$ for $15 \mathrm{~min}$ at $4{ }^{\circ} \mathrm{C}$. The ileal supernatant and plasma were used to detect the concentrations of interleukin $1 \beta$ (IL-1 $\beta$ ), IL-6, and tumor necrosis factor $\alpha$ (TNF- $\alpha$ ) with commercial ELISA kits (Beijing 4A Biotech Co., Ltd., Beijing, China) according to the manufacturer's instructions.

\section{Small intestinal morphology and goblet cell counting}

The histomorphology and the count of goblet cells in the jejunum were determined according to our previous study [30]. Briefly, each tissue sample was used to prepare five slides and each slide had three sections $(5 \mu \mathrm{m}$ thickness), which were stained with hematoxylin and eosin for intestinal morphology analysis of 20 intact well-oriented crypt-villus units each section (Scion Image software, Version 4.02, 2004). Periodic Acid Schiff and Alcian Blue (PAS-AB) were used for counting goblet cells. The number of positively stained goblet cells was measured (NIS-Elements BR 2.3; Nikon France SAS), and the values obtained from 10 villi by each small-intestinal segment were averaged.

\section{Total RNA extraction and real-time reverse transcription PCR}

Total RNA was extracted from frozen ileal samples using Trizol reagent (TaKaRa Biotechnology, Dalian, China) according to the manufacturer's instructions. The quality of the RNA was determined by electrophoresis on $1.0 \%$ agarose gel, and the purity of RNA was assessed by evaluating the OD260:OD280 ratio using a nucleic acid analyzer (Beckman DU-800; Beckman Coulter, Inc., Brea, CA) [31]. Both genomic DNA removal and reverse transcription were performed using PrimeScript RT reagent kit with gDNA eraser (TaKaRa Biotechnology) according to the manufacturer's guidelines. Real-time PCR was performed using SYBR Premix Ex Taq (Tli RNaseH Plus) qPCR kit (TaKaRa Biotechnology Dalian Co., Ltd., Dalian, China) with ABI-7900HT Fast Real-Time PCR System (Applied Biosystems, Foster City, CA, USA). The PCR reaction consisted of 5.0 $\mu \mathrm{L}$ SYBR Premix Ex Taq (2x), $0.4 \mu \mathrm{L}$ forward primer $(10 \mu \mathrm{mol} / \mathrm{L}), 0.4 \mu \mathrm{L}$ reverse primer $(10 \mu \mathrm{mol} / \mathrm{L}), 0.2 \mu \mathrm{L}$ ROX reference dye $(50 \times)$, 1.0 $\mathrm{LL} \mathrm{cDNA}$, and $3.0 \mu \mathrm{L}$ double-distilled water in a total volume of $10 \mu \mathrm{L}$. The PCR procedure was as follows: pre-denaturating at $95^{\circ} \mathrm{C}$ for $30 \mathrm{~s}, 40$ cycles of denaturation at $95^{\circ} \mathrm{C}$ for $5 \mathrm{~s}$, annealing at $60^{\circ} \mathrm{C}$ for $34 \mathrm{~s}$, and extension at $95^{\circ} \mathrm{C}$ for $15 \mathrm{~s}$ and a cycle of final extension at $72^{\circ} \mathrm{C}$ for $6 \mathrm{~min}$. At the end of amplifcation, melting curve analysis was performed to verify specifc amplifcations. $\beta$-actin was used as an internal reference gene to normalize the expression of target genes according to the $2^{-\Delta \Delta C t}$ method described by Livak and Schmittgen [32], where $\Delta \Delta \mathrm{Ct}=\left(\mathrm{Ct}_{\text {target }}-\mathrm{Ct}_{\beta \text {-actin }}\right)_{\text {treatment }}-\left(\mathrm{Ct}_{\text {target }}\right.$
- $\left.\mathrm{Ct}_{\beta \text {-actin }}\right)_{\text {control }}$. The mRNA level of each target gene for CON-ETEC group was set to 1.0. All samples were run in triplicate, and the primers are shown in Table 1.

\section{S rRNA gene sequencing}

The total genomic DNA was extracted from a random subset of colonic digesta $(n=6)$ using the QIAamp DNA stool Mini Kit (Qiagen, GmbH Hilden, Germany) according to the manufacturer's protocols. The concentration and purity of the extracted genomic DNA were measured using a NanoDrop ND-1000 Spectrophotometer (NanoDrop Technologies Inc., Wilmington, DE, USA). The integrity of the extracted genomic DNA was determined by electrophoresis on $1 \%(w / v)$ agarose gels [33]. Extracted fecal DNA samples were sent to Novogene Bioinformatics Technology (Beijing, China) to perform amplicon pyrosequencing on the Illumina HiSeq PE250 platforms. The V4 hypervariable region of the $16 \mathrm{~S}$ rRNA gene was amplified by PCR with primers 515F (5'-GTGCCAGCMGCCGCGGTAA-3') and 806R (5'-GGACTACHVGGGTWTCTAAT-3'). The effective tags were mapped to OTUs using Uparse v7.0.1001 at 97\% sequence similarity. Representative sequences for each OTU were selected. The Ribosomal Database Project (RDP) classifier Version 2.2 was used to assign a taxonomic rank to each representative sequence. The relative abundance of each OTU was examined at different taxonomic levels. Diversity within communities (Alpha diversity) calculations and taxonomic community assessments were performed by Qiime 1.7.0. Principal coordinates analysis plots were produced using unweighted UniFrac metrics.

\section{SCFAs analysis}

The SCFAs concentrations in the colonic digesta were measured using a gas chromatographic method as described by Chen et al. [34]. Briefly, digesta samples (1 g) were thawed and suspended in $2 \mathrm{~mL}$ of distilled water in a screw-capped tube. After being vortexed, the suspension liquid was centrifuged $(12,000 \times g)$ at $4{ }^{\circ} \mathrm{C}$ for $10 \mathrm{~min}$. The supernatant $(2 \mathrm{~mL})$ was transferred into Eppendorf tubes and mixed with $0.2 \mathrm{~mL}$ metaphosphoric acid. The tubes were placed at $4{ }^{\circ} \mathrm{C}$ for $30 \mathrm{~min}$ and then centrifuged $(12,000 \times g)$ again at $4{ }^{\circ} \mathrm{C}$ for $10 \mathrm{~min}$. Aliquot of the supernatant $(1 \mu \mathrm{L})$ was analyzed using a Varian CP-3800 gas chromatograph (Agilent Technologies, Santa Clara, CA, USA) equipped with a flame ionization detector and a polyethene glycol packed column $(0.32 \mathrm{~mm}$ internal diameter, $30 \mathrm{~m}$ length and $0.25 \mu \mathrm{m}$ film thickness). SCFAs were quantified using external standard curves from 0.5 to $100 \mu \mathrm{mol} / \mathrm{mL}$ of the respective authentic organic acids (Fluka, Switzerland) [35]. 
Table 1 Primer sequences of target and reference genes

\begin{tabular}{|c|c|c|c|}
\hline Gene & Primer sequence $\left(5^{\prime} \rightarrow 3^{\prime}\right)$ & Product, bp & GenBank accession \\
\hline \multirow[t]{2}{*}{ TLR-9 } & Forward: AATCCAGTCGGAGATGTTTGCT & 79 & AY859728 \\
\hline & Reverse: GACCGCCTGGGAGATGCT & & \\
\hline \multirow[t]{2}{*}{ TLR-2 } & Forward: TCGAAAAGAGCCAGAAAACCAT & 58 & NM213761 \\
\hline & Reverse: CTTGCACCACTCGCTCTTCA & & \\
\hline \multirow[t]{2}{*}{ TLR-4 } & Forward: AGAAAATATGGCAGAGGTGAAAGC & 64 & GQ304754 \\
\hline & Reverse: CTTCGTCCTGGCTGGAGTAGA & & \\
\hline \multirow[t]{2}{*}{ MyD88 } & Forward: GTGCCGTCGGATGGTAGTG & 65 & NM001099923 \\
\hline & Reverse: TCTGGAAGTCACATTCCTTGCTT & & \\
\hline \multirow[t]{2}{*}{ TRAF-6 } & Forward: GCTGCATCTATGGCATTGAAG & 70 & AJ606305.1 \\
\hline & Reverse: CCACAGATAACATTTGCCAAAGG & & \\
\hline \multirow[t]{2}{*}{$N F-K B$} & Forward: TGCTGGACCCAAGGACATG & 60 & AK348766.1 \\
\hline & Reverse: CTCCCTTCTGCAACAACACGTA & & \\
\hline \multirow[t]{2}{*}{ IL-6 } & Forward: GATGCTTCCAATCTGGGTTCA & 62 & M80258.1 \\
\hline & Reverse: CACAAGACCGGTGGTGATTCT & & \\
\hline \multirow[t]{2}{*}{ Claudin-1 } & Forward: TCTTAGTTGCCACAGCATGG & 106 & NM001244539 \\
\hline & Reverse: CCAGTGAAGAGAGCCTGACC & & \\
\hline \multirow[t]{2}{*}{ Occludin } & Forward: TTCATTGCTGCATTGGTGAT & 113 & NM001163647 \\
\hline & Reverse: ACCATCACACCCAGGATAGC & & \\
\hline \multirow[t]{2}{*}{ ZO-1 } & Forward: CCGCCTCCTGAGTTTGATAG & 97 & AJ318101 \\
\hline & Reverse: CAGCTTTAGGCACTGTGCTG & & \\
\hline \multirow[t]{2}{*}{$\beta$-actin } & Forward: GGCGCCCAGCACGAT & 66 & DQ845171.1 \\
\hline & Reverse: CCGATCCACACGGAGTACTTG & & \\
\hline
\end{tabular}

TLR Toll-like receptor, MyD88 myeloid differentiation factor 88, TRAF-6 TNF receptor-associated factor 6, NF- $K B$ nuclear transcription factor kappa B, IL interleukin, ZO-1 zonula occludens-1

\section{Statistical analysis}

All data were expressed as means with their standard errors. Growth performance and diarrhea score of piglets before ETEC challenge was analyzed using the unpaired $t$ test. The data in the challenge study were analyzed as a $2 \times 2$ factorial with the general linear model procedures of the Statistical Analysis Package. The model factors included the effects of E. faecium administration (with or without E. faecium in diets), ETEC infection (ETEC unchallenged or challenged), and their interaction. Data were analyzed using SAS (version 9.4; SAS Inst. Inc., Cary, NC, USA). For analysis of intestinal microbiota, data of relative abundance at phylum and genus levels were logtransformed before statistical analysis. Significant differences were set at $P \leq 0.05$, whereas $0.05<P<0.10$ was considered a tendency.

\section{Results}

\section{Growth performance}

As shown in Table 2, there were no significant differences $(P>0.05)$ between the two groups of piglets for their ADG and fecal score from the age of 2 to 8 days.

\section{Fecal score}

As shown in Fig. 1, piglets challenged with ETEC had greater fecal score than that of non-challenged piglets at $4,8,12$, and $16 \mathrm{~h}$ post challenge $(P<0.05)$, whereas the PRO administration was able to alleviate the fecal score at 12 and $16 \mathrm{~h}$ post challenge $(P<0.05)$. In addition, there was an interaction between PRO and ETEC challenge at $12 \mathrm{~h}$ and $16 \mathrm{~h}$ post challenge $(P<0.05)$.

Table 2 Effect of E. faecium on growth performance and fecal score of piglets

\begin{tabular}{llll}
\hline Items & CON & PRO & $P$-value \\
\hline Initial BW, kg & $1.70 \pm 0.05$ & $1.73 \pm 0.05$ & 0.70 \\
Final BW, kg & $3.09 \pm 0.07$ & $3.19 \pm 0.07$ & 0.37 \\
ADG, g/d & $199 \pm 7.00$ & $209 \pm 8.00$ & 0.37 \\
Fecal score $^{1}$ & $0.07 \pm 0.03$ & $0.04 \pm 0.02$ & 0.27 \\
\hline
\end{tabular}

Data are presented as means \pm SE ( $n=16$; pen was used as experimental unit) CON control group, PRO Enterococcus faecium-supplemented group, $B W$ body weight, $A D G$ average daily gain

${ }^{1}$ Fecal score $=($ Sum of the fecal score over the period $) /($ experiment days $)$ 


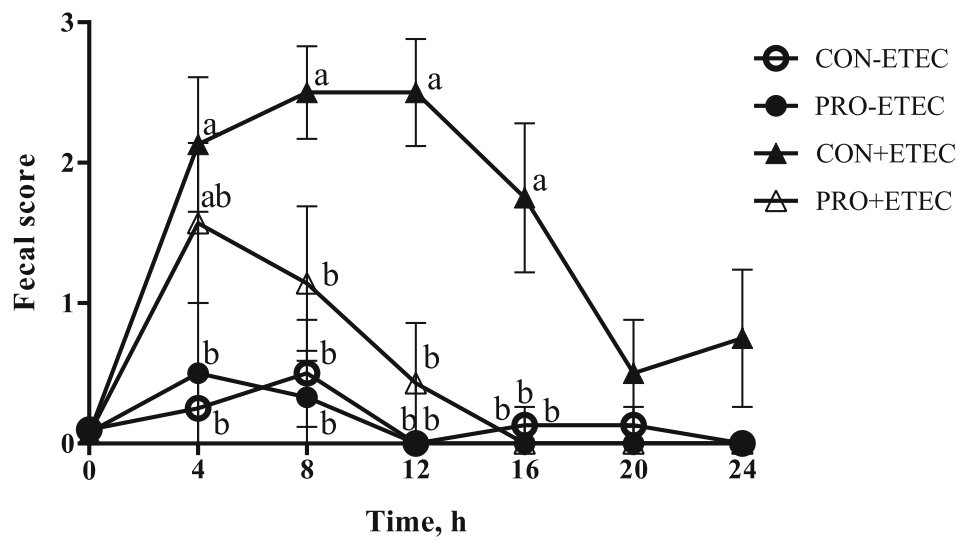

Fig. 1 Effect of E. faecium on fecal score of piglets challenged with ETEC K88. Values are means, with their standard errors represented by vertical bars $(n=8)$. CON-ETEC, control group infusing the essential medium; CON+ETEC, control group infusing the Escherichia coli; PRO-ETEC, Enterococcus faecium-supplemented group infusing the essential medium; PRO+ETEC, Enterococcus faecium-supplemented group infusing the

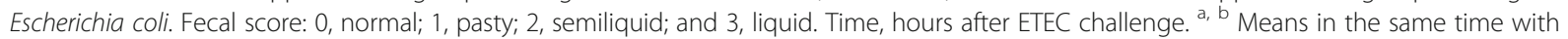
different superscripts are significantly different $(P<0.05)$

\section{Routine blood examination and composition of peripheral lymphocyte percentages}

ETEC challenge markedly increased the count and percentage of lymphocytes $(P<0.05)$ (Table 3$)$. The count and percentage of lymphocytes were increased $(P<0.05)$ in the CON+ETEC group than in the CON-ETEC group, whereas no significant difference was observed between the PRO groups. The composition of peripheral lymphocyte percentages was not markedly affected by PRO $(P>0.10)$ or ETEC $(P>0.10)$, whereas there was an interaction between PRO and ETEC challenge for the percentage of $\mathrm{CD}^{+} \mathrm{T}$ cells $(P<0.05)$ (Fig. 2). The percentage of $\mathrm{CD}^{+} \mathrm{T}$ cells was lower $(P<0.05)$ in the PRO-ETEC group than that in the CON-ETEC group.

\section{Inflammatory cytokine concentrations}

As shown in Table 4, ETEC challenge elevated the concentrations of IL- $1 \beta$ in plasma and TNF- $\alpha$ in ileal mu$\operatorname{cosa}(P<0.05)$. The concentrations of IL-1 $\beta$ in plasma and TNF- $\alpha$ in ileal mucosa were increased $(P<0.05)$ in the CON+ETEC group than that in the CON-ETEC group, whereas no significant difference was observed between the PRO+ETEC and PRO-ETEC groups.

Table 3 Effect of E. faecium on blood routine parameters of piglets challenged with ETEC K88

\begin{tabular}{|c|c|c|c|c|c|c|c|}
\hline \multirow[t]{2}{*}{ Items } & \multicolumn{2}{|l|}{-ETEC } & \multicolumn{2}{|l|}{+ ETEC } & \multicolumn{3}{|c|}{$P$-value } \\
\hline & $\mathrm{CON}$ & PRO & $\mathrm{CON}$ & PRO & $\mathrm{PRO}$ & ETEC & PROXETEC \\
\hline White blood cell, $10^{9} / \mathrm{L}$ & $7.26 \pm 1.20$ & $8.80 \pm 1.67$ & $7.77 \pm 0.98$ & $8.16 \pm 1.22$ & 0.45 & 0.96 & 0.65 \\
\hline Lymphocytes, $10^{9} / \mathrm{L}$ & $1.46 \pm 0.16^{b}$ & $1.85 \pm 0.19^{b}$ & $2.96 \pm 0.62^{a}$ & $2.60 \pm 0.51^{a b}$ & 0.97 & 0.03 & 0.44 \\
\hline Neutrophils, $10^{9} / \mathrm{L}$ & $4.55 \pm 0.62$ & $4.76 \pm 0.49$ & $4.23 \pm 0.77$ & $5.23 \pm 0.49$ & 0.36 & 0.91 & 0.54 \\
\hline Intermediate cell, $10^{9} / \mathrm{L}$ & $0.40 \pm 0.04$ & $0.65 \pm 0.20$ & $0.59 \pm 0.13$ & $0.56 \pm 0.14$ & 0.44 & 0.74 & 0.35 \\
\hline Lymphocytes, \% & $21.45 \pm 2.51^{b}$ & $25.05 \pm 3.58^{a b}$ & $37.24 \pm 5.83^{a}$ & $29.23 \pm 2.60^{a b}$ & 0.61 & 0.03 & 0.19 \\
\hline Neutrophils, \% & $69.40 \pm 2.42$ & $58.28 \pm 6.87$ & $54.73 \pm 6.71$ & $63.42 \pm 3.75$ & 0.82 & 0.39 & 0.08 \\
\hline Intermediate cell, \% & $6.04 \pm 1.16$ & $6.77 \pm 1.31$ & $8.03 \pm 1.71$ & $6.12 \pm 0.87$ & 0.70 & 0.66 & 0.38 \\
\hline Red blood cell, $10^{12} / \mathrm{L}$ & $9.17 \pm 0.37$ & $8.77 \pm 0.67$ & $9.35 \pm 0.47$ & $9.20 \pm 0.31$ & 0.57 & 0.52 & 0.80 \\
\hline Haematocrit, \% & $78.34 \pm 3.00$ & $73.35 \pm 6.70$ & $76.69 \pm 2.46$ & $76.30 \pm 1.22$ & 0.44 & 0.85 & 0.51 \\
\hline Mean corpuscular volume, fL & $85.56 \pm 0.70$ & $83.60 \pm 3.81$ & $82.61 \pm 2.12$ & $83.28 \pm 2.21$ & 0.79 & 0.50 & 0.58 \\
\hline Platelet, $10^{9} / \mathrm{L}$ & $576.00 \pm 134.95$ & $441.50 \pm 82.92$ & $508.42 \pm 109.58$ & $636.20 \pm 123.37$ & 0.98 & 0.61 & 0.29 \\
\hline Thrombocytocrit, \% & $0.72 \pm 0.24$ & $0.45 \pm 0.10$ & $0.61 \pm 0.17$ & $0.79 \pm 0.23$ & 0.82 & 0.60 & 0.29 \\
\hline
\end{tabular}

Data are presented as means \pm SE $(n=8)$

-ETEC, infusing the essential medium; +ETEC, infusing the Escherichia coli; CON, control group; PRO, Enterococcus faecium-supplemented group

a, b Means within a row with different superscripts are significantly different $(P<0.05)$ 

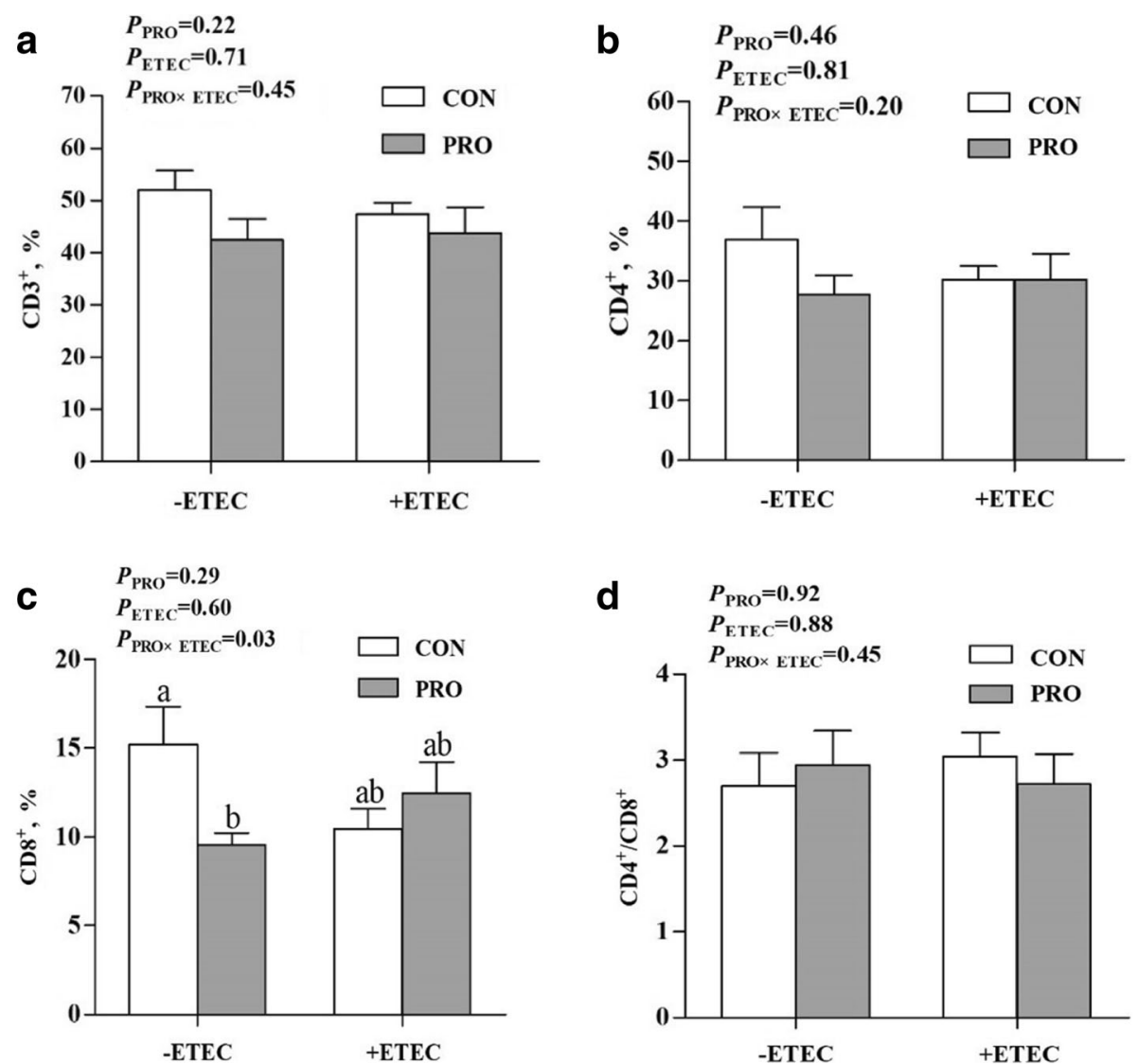

Fig. 2 Effect of $E$. faecium on the composition of peripheral lymphocyte percentages of piglets challenged with ETEC K88. a, percentage of CD3 ${ }^{+}$ T-lymphocytes; $\mathbf{b}$, percentage of CD4 ${ }^{+}$T-lymphocytes; $\mathbf{c}$, percentage of $\mathrm{CD} 8^{+}$T-lymphocytes; $\mathbf{d}$, ratio of $\mathrm{CD} 4^{+}$to $\mathrm{CD} 8^{+}$. -ETEC, infusing the essential medium; +ETEC, infusing the Escherichia coli; CON, control group; PRO, Enterococcus faecium-supplemented group. Values are means, with their standard errors represented by vertical bars $(n=8) .{ }^{\text {a, b }}$ Mean values with different superscript letters are significantly different $(P<0.05)$

\section{Intestinal morphology and goblet cell density}

The ETEC challenge reduced villous height and the ratio of villous height:crypt depth $(\mathrm{VCR})$ of jejunum $(P<0.05)$ and increased crypt depth of jejunum $(P<0.05)$ (Fig. 3a-c). There was an interaction between PRO and ETEC challenge for jejunal VCR $(P<0.05)$. Jejunal VCR was lower $(P<0.05)$ in the CON+ETEC group than in the CON-ETEC group, whereas jejunal VCR did not differ $(P>0.05)$ between the PRO+ETEC and PRO-ETEC groups. The number of goblet cells in the jejunum was decreased $(P<0.05)$ by ETEC

Table 4 Effect of E. faecium on cytokines concentrations in the plasma and ileal mucosa of piglets challenged with ETEC K88

\begin{tabular}{|c|c|c|c|c|c|c|c|}
\hline \multirow[t]{2}{*}{ Items } & \multicolumn{2}{|l|}{-ETEC } & \multicolumn{2}{|l|}{+ ETEC } & \multicolumn{3}{|c|}{$P$-value } \\
\hline & CON & PRO & CON & PRO & PRO & ETEC & PROXETEC \\
\hline \multicolumn{8}{|l|}{ Plasma } \\
\hline $\mathrm{IL}-1 \beta, \mathrm{ng} / \mathrm{mL}$ & $0.78 \pm 0.07^{b}$ & $0.93 \pm 0.15^{\mathrm{ab}}$ & $1.32 \pm 0.20^{a}$ & $1.13 \pm 0.21^{\mathrm{ab}}$ & 0.93 & 0.04 & 0.33 \\
\hline IL-6, ng/mL & $11.04 \pm 1.25$ & $11.07 \pm 1.90$ & $11.31 \pm 1.03$ & $12.32 \pm 1.47$ & 0.71 & 0.59 & 0.72 \\
\hline TNF-a, pg/mL & $49.16 \pm 6.44$ & $51.29 \pm 5.42$ & $57.20 \pm 6.50$ & $42.81 \pm 4.53$ & 0.38 & 0.97 & 0.24 \\
\hline \multicolumn{8}{|l|}{ Ileal mucosa } \\
\hline $\mathrm{IL}-1 \beta, \mathrm{ng} / \mathrm{mL}$ & $5.22 \pm 0.85$ & $5.08 \pm 0.51$ & $5.67 \pm 0.92$ & $5.87 \pm 0.75$ & 0.97 & 0.45 & 0.83 \\
\hline IL-6, ng/mL & $9.22 \pm 0.74$ & $10.30 \pm 0.42$ & $11.04 \pm 0.59$ & $10.84 \pm 0.79$ & 0.54 & 0.11 & 0.37 \\
\hline TNF-a, ng/mL & $0.90 \pm 0.06^{\mathrm{b}}$ & $0.88 \pm 0.06^{\mathrm{b}}$ & $1.15 \pm 0.07^{a}$ & $1.02 \pm 0.06^{\mathrm{ab}}$ & 0.25 & $<0.01$ & 0.41 \\
\hline
\end{tabular}

Data are presented as means \pm SE $(n=8)$

-ETEC, infusing the essential medium; +ETEC, infusing the Escherichia coli; CON, control group; PRO, Enterococcus faecium-supplemented group

a, b Means within a row with different superscripts are significantly different $(P<0.05)$ 

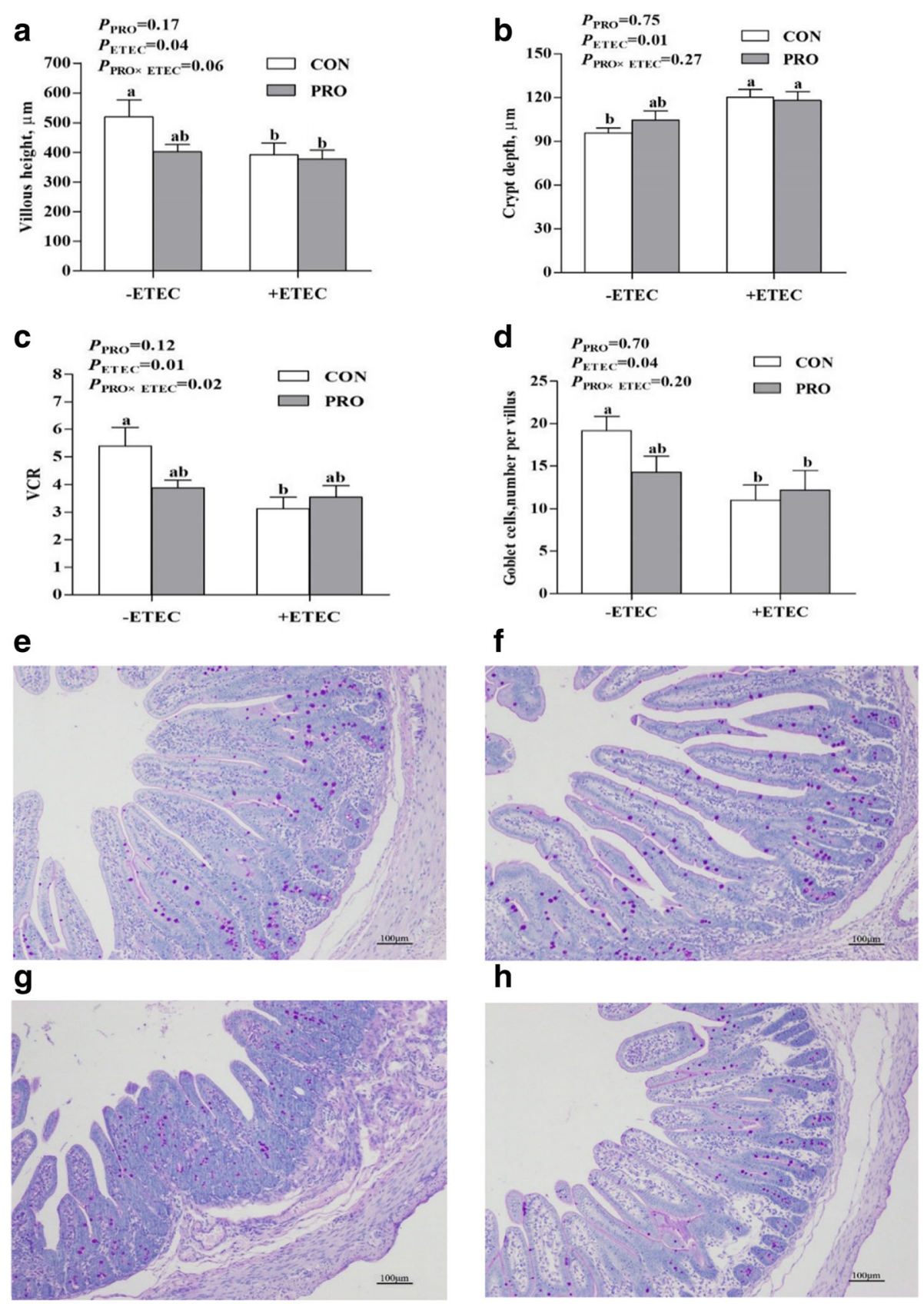

Fig. 3 Effect of E. faecium on the intestinal histomorphology and number of goblet cells in the jejunum of piglets challenged with Escherichia coli (ETEC) K88. a, villous height; $\mathbf{b}$, crypt depth; c the ratio of villous height:crypt depth (VCR); $\mathbf{d}$, number of goblet cells; e-h, Representative micrographs of goblet cell staining carried out on paraformaldehyde-fixed sections from the jejunum (100x magnification) of piglets challenged with ETEC K88 (e, CON-ETEC; f, PRO-ETEC; $\mathbf{g}$, CON+ETEC; $\mathbf{h}$, PRO+ETEC). -ETEC, infusing the essential medium; +ETEC, infusing the Escherichia coli; CON, control group; PRO, Enterococcus faecium-supplemented group; VCR, Villous height:crypt depth ratio. Values are means, with their standard errors represented by vertical bars $(n=8)$. ${ }^{a, b}$ Means values with different superscript letters are significantly different $(P<0.05)$. For VCR $(\mathbf{c})$, the superscript letters referred to significant effect of ETEC

challenge (Fig. 3d-h). Following ETEC challenge, jejunal goblet cell numbers were decreased $(P<0.05)$ in the CON groups, whereas no significant difference was observed between the PRO groups.

\section{Gene expression in the ileum}

The mRNA abundances of TLR-2 and NF-KB $(P<0.05)$ in the ileum were increased $(P<0.05)$ by ETEC challenge (Fig. 4). Following ETEC challenge, the mRNA 
abundances of $T L R-2$ and $N F-\kappa B$ were increased $(P<0.05)$ in the CON groups, whereas no difference was observed between the PRO groups. Ileal TLR-2 mRNA abundance was affected by PRO $(P<0.05)$ and the $\mathrm{PRO} \times \mathrm{ETEC}$ interaction $(P<0.05)$. In addition, piglets in PRO groups had lower mRNA abundances of TLR-9 and NF-KB $(P<0.05)$ in the ileum when compared to those in $\mathrm{CON}$ groups. Furthermore, piglets challenged with ETEC had lower mRNA abundance of claudin-1 $(P<0.05)$ in the ileum, and the PRO supplementation was able to increase the mRNA abundance of claudin-1 $(P<0.05$, Fig. 5). The mRNA abundance of Claudin- 1 was decreased $(P<0.05)$ in the CON+ETEC group than in the CON-ETEC group, whereas no difference was observed between the PRO groups.

\section{Gut bacterial community structure}

A total of 1,943,803 high-quality sequences were obtained from 4 groups, with an average of 80,991 sequences per sample. All of OTUs were defined at $97 \%$ species similarity level, 12,894 OTUs were obtained from colonic digesta samples, with an average of 537 OTUs per sample. Four alpha diversity measures were calculated including observed species, Shannon index, Chao 1 index, and phylogenetic diversity (PD) tree (Additional file 1: Table S1). However, these measures were not significantly affected by PRO, ETEC challenge, or the interaction between PRO and ETEC challenge. In addition, the relationships among bacterial communities from different treatments were represented by principal coordinate analysis ( $\mathrm{PCoA})$, and the results showed that the microbial communities of piglets in the four groups were not significantly different (Additional file 1: Figure S2).
At the phylum level, there were six phyla with a relative abundance greater than $0.5 \%$ in at least one experimental group: Proteobacteria, Bacteroidetes, Firmicutes, Fusobacteria, Planctomycetes, Lentisphaerae (Table 5). Of these six phyla, Bacteroidetes predominated in all samples, with a relative abundance of $42.27 \%-47.63 \%$, followed by Firmicutes, at $19.03 \%-33.46 \%$. Piglets challenged with ETEC tended to increase $(P=0.07)$ the relative abundance of Proteobacteria, and the PRO supplementation increased $(P=0.05)$ the relative abundance of Verrucomicrobia.

The heatmap in Fig. 6 shows the relative abundances of various bacteria at the genus level in the different groups. Compared with CON groups, piglets in PRO groups had lower abundance of Bilophila $(P<0.05)$, and had a tendency for lower abundance of Parabacteroides $(P=0.06)$. In addition, piglets challenged with ETEC had lower abundance of Lachnoclostridium $(P<0.05)$, and tended to decrease the abundance of Ruminococcaceae NK4A214_group $(P=0.07)$, Prevotella_7 $(P=0.08)$ and Lactobacillus $(P=0.08)$, whereas the relative abundance of Escherichia-Shigella and Prevotellaceae_NK3B31_ group were significantly increased $(P \leq 0.05)$. Meanwhile, the decreased Lachnoclostridium at genus level caused by ETEC were relieved by feeding E. faecium (Additional file 1: Table S2).

\section{SCFAs concentrations}

As shown in Additional file 1: Table S3, concentrations of acetate, propionic acid and butyric acid in colonic digesta were not markedly affected by PRO or ETEC challenge $(P>0.05)$.

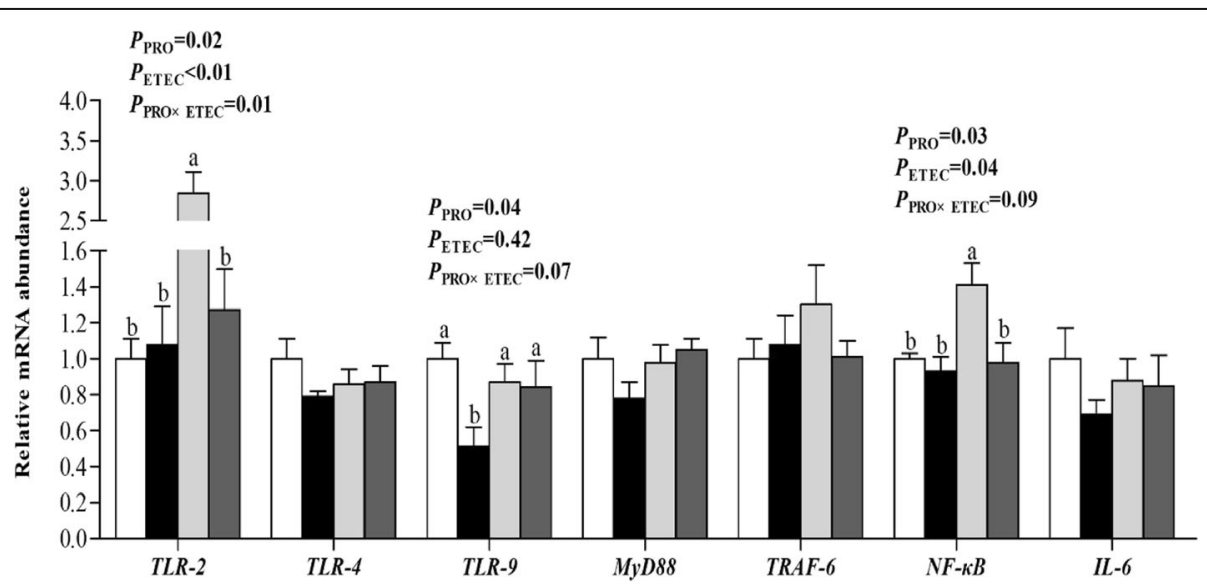

Fig. 4 Effect of E. faecium on mRNA abundance of innate immune-related genes in the ileum of piglets challenged with ETEC K88. Values are means, with their standard errors represented by vertical bars $(n=8)$. $\square$, CON-ETEC; $\square$,PRO-ETEC; $\square$, CON+ETEC; $\square$, PRO+ETEC. TLR, Toll-like receptor; MyD88, myeloid differentiation factor 88; TRAF-6, TNF receptor-associated factor 6; NF-KB, nuclear transcription factor kappa B; $I L$, interleukin. ${ }^{a, b}$ Mean values with different superscript letters are significantly different $(P<0.05)$. For $T L R-2$ and $N F-k B$, the superscript letters referred to significant effect of ETEC 


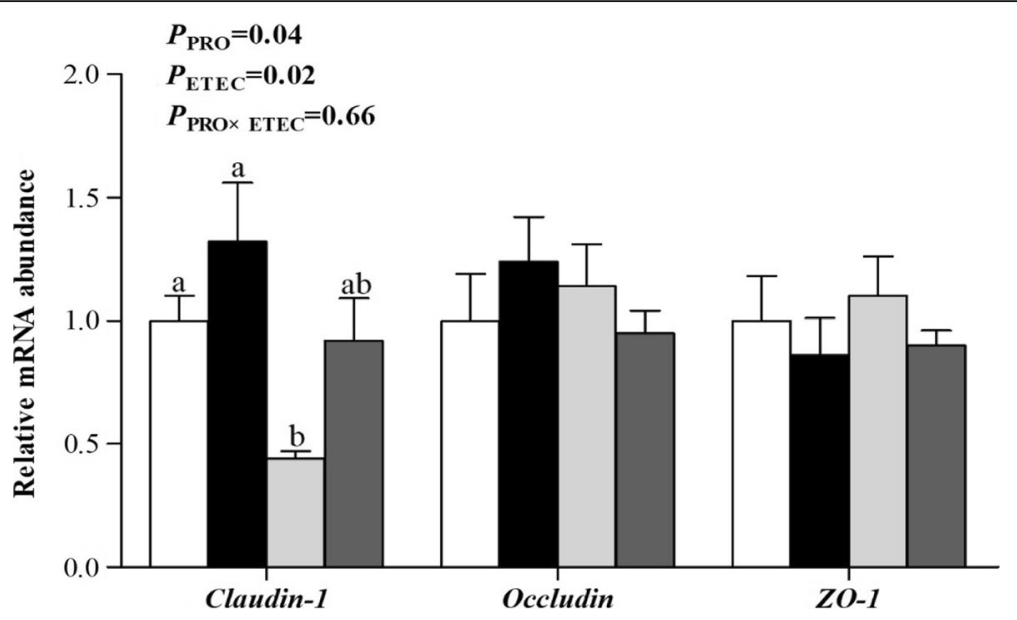

Fig. 5 Effect of $E$. faecium on mRNA abundance of tight junction proteins in the ileum of piglets challenged with ETEC K88. Values are means, with their standard errors represented by vertical bars $(n=8) . \square$, CON-ETEC; $\square$ PRO-ETEC; $\square$, CON+ETEC; $\square$, PRO+ETEC. ZO-1, ZOnula occludens-1. ${ }^{\mathrm{a}, \mathrm{b}}$ Means values with different superscript letters are significantly different $(P<0.05)$. For claudin-1, the superscript letters referred to significant effect of ETEC

\section{Discussion}

Oral administration of E. faecium probiotics in humans has been considered to be effective in the prevention of antibiotic-associated diarrhea [36] and in the treatment of diarrhoeal disorders in children [37]. In addition, $E$. faecium has been used as a probiotic in livestock animal to improve growth performance and intestinal health [38], and reduce diarrhea incidence [17, 19]. Büsing and Zeyner suggested that oral administration of E. faecium NCIMB 10415 could improve the growth rate and mitigate incidence and severity of diarrhoea in suckling piglets [13]. However, some researchers suggested $E$. faecium failed to affect the growth performance of piglets $[39,40]$. In the current study, we found the oral administration of E. faecium did not show beneficial effects on the growth rate and diarrhea severity of 2- to 8 -day-old piglets. The discrepancies between studies might be due to different strains and dose of E. faecium, as well as the length of time E. faecium was supplied. It is considered that growth promoters are more effective when the livestock animals suffered environmental and nutritional challenges [39]. Accordingly, the positive effect of E. faecium may be obvious under the condition of pathogenic pressure, which was confirmed in the ETEC challenge study, indicating that oral administration of E. faecium attenuated the diarrhea severity in sucking piglets challenged by ETEC.

The villous height and the crypt depth are important indicators to reflect the digestive and absorptive functions of the small intestine [41]. The shortening of the

Table 5 Effect of E. faecium on the relative abundance of the top 10 microbial phylum in the colon of piglets challenged with ETEC K88

\begin{tabular}{|c|c|c|c|c|c|c|c|}
\hline \multirow[t]{2}{*}{ Items } & \multicolumn{2}{|l|}{-ETEC } & \multicolumn{2}{|l|}{+ ETEC } & \multicolumn{3}{|c|}{$P$-value } \\
\hline & $\mathrm{CON}$ & PRO & $\mathrm{CON}$ & PRO & PRO & ETEC & PRO $\times$ ETEC \\
\hline Proteobacteria & $15.91 \pm 2.91$ & $12.06 \pm 2.40$ & $18.38 \pm 1.41$ & $17.81 \pm 2.91$ & 0.23 & 0.07 & 0.48 \\
\hline Bacteroidetes & $47.63 \pm 3.45$ & $44.04 \pm 3.53$ & $47.42 \pm 4.38$ & $42.27 \pm 5.95$ & 0.29 & 0.68 & 0.75 \\
\hline Firmicutes & $24.40 \pm 4.19$ & $33.46 \pm 8.34$ & $19.03 \pm 1.80$ & $29.66 \pm 7.07$ & 0.37 & 0.52 & 0.95 \\
\hline Fusobacteria & $11.25 \pm 4.60$ & $9.06 \pm 5.56$ & $14.73 \pm 5.02$ & $9.29 \pm 6.97$ & 0.11 & 0.98 & 0.67 \\
\hline Verrucomicrobia & $0.01 \pm 0.01$ & $0.01 \pm 0.00$ & $0.02 \pm 0.02$ & $0.25 \pm 0.23$ & 0.05 & 0.82 & 0.53 \\
\hline Planctomycetes & $0.04 \pm 0.02$ & $0.69 \pm 0.64$ & $0.06 \pm 0.04$ & $0.11 \pm 0.08$ & 0.24 & 0.14 & 0.68 \\
\hline Lentisphaerae & $0.51 \pm 0.30$ & $0.29 \pm 0.09$ & $0.13 \pm 0.11$ & $0.25 \pm 0.13$ & 0.23 & 0.11 & 0.43 \\
\hline Spirochaetes & $0.03 \pm 0.02$ & $0.14 \pm 0.10$ & $0.03 \pm 0.02$ & $0.12 \pm 0.06$ & 0.92 & 0.59 & 0.64 \\
\hline Euryarchaeota & $0.08 \pm 0.04$ & $0.07 \pm 0.05$ & $0.07 \pm 0.06$ & $0.10 \pm 0.05$ & 0.42 & 0.98 & 0.58 \\
\hline Actinobacteria & $0.07 \pm 0.03$ & $0.09 \pm 0.04$ & $0.04 \pm 0.01$ & $0.08 \pm 0.03$ & 0.29 & 0.47 & 0.59 \\
\hline
\end{tabular}

Data are presented as means \pm SE $(n=6)$

-ETEC, infusing the essential medium; +ETEC, infusing the Escherichia coli; CON, control group; PRO, Enterococcus faecium-supplemented group 


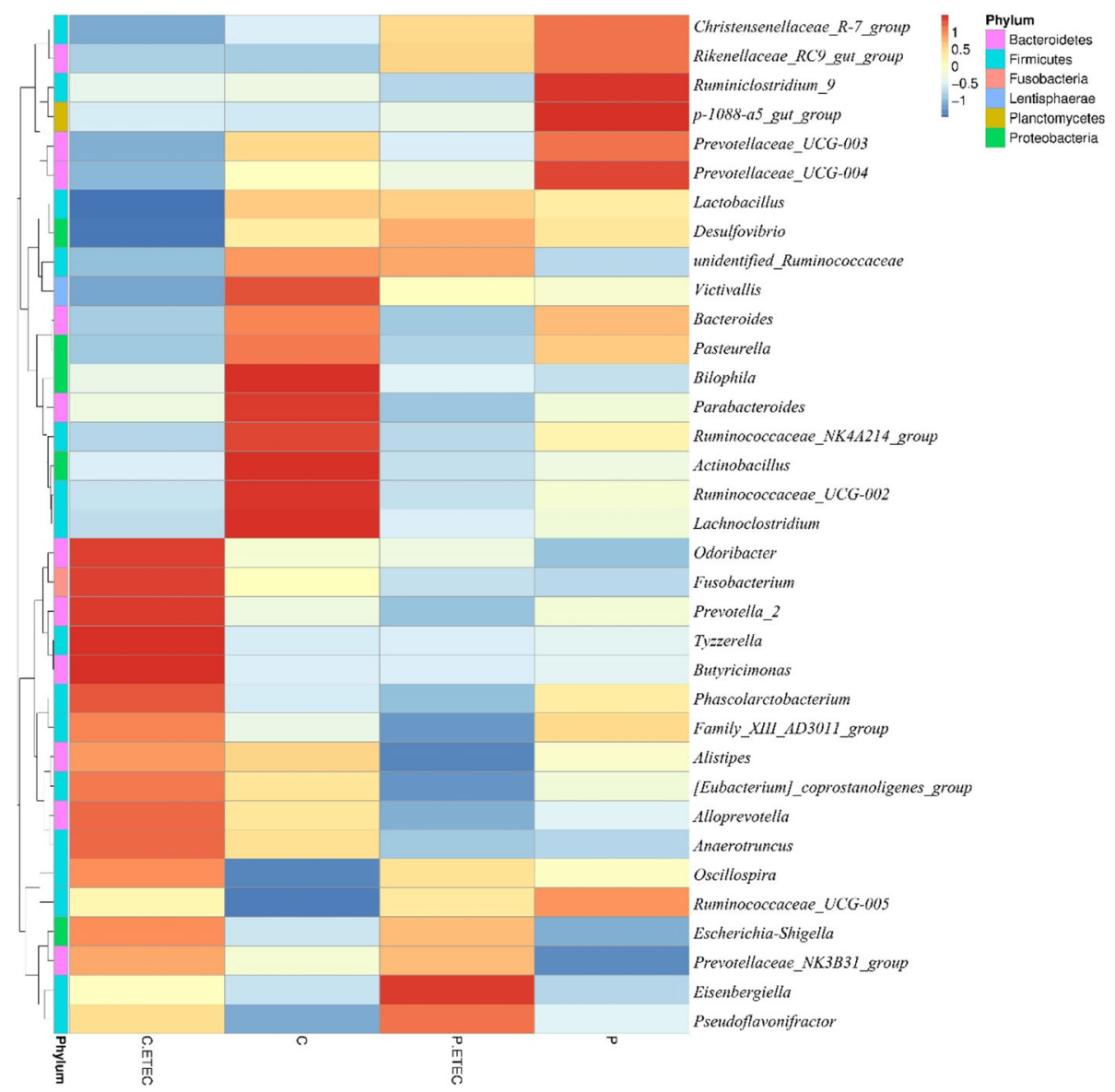

Fig. 6 Effect of E. faecium on the relative abundance of microbial genera in the colon of piglets challenged with ETEC K88. The relative percentages (\%) of the bacterial genus are indicated by varying color intensities according to the legend at the top of the figure. Bacterial genus names are listed on the right side of the heatmap, and the phylum names are listed on the left. The intensity of the cell color represents the abundance of the amplicons belonging to each genus. C.ETEC, CON+ETEC; C, CON-ETEC; P.ETEC, PRO+ETEC; P, PRO-ETEC

villous height may imply the decreased surface area for nutrient absorption, and a deeper crypt may suggest a faster turnover of new villous cells [42]. The VCR is a useful indicator for assessing intestinal function and health [43]. This study showed that piglets challenged with ETEC had deeper crypts, and reduced VCR in the jejunum. However, the oral administration of E. faecium could attenuate the effect of ETEC challenge on the morphology of jejunum, which is in accordance with the lower diarrhea score in piglets supplemented with $E$. faecium during the 24-h post challenge. Supportively, Xie et al. reported that piglets fed the diet containing $E$. faecium had increased villus height in the jejunum and reduced crypt depth in the ileum [38].

Infection with ETEC is often associated with diarrhea and impaired intestinal barrier function. Goblet cells producing mucins are the important component of nonspecific intestinal barrier, partly protecting animals against bacterial and fungal invasion [44]. The decrease in number of goblet cells may decrease the mucin secretion of mucosa [45], which would be detrimental for the mucosal barrier. In this study, dietary E. faecium supplementation attenuated the effect of ETEC challenge on the number of goblet cells, which suggests the effect of $E$. faecium supplementation on improving mucosal barrier of piglets under ETEC challenge. Likewise, the oral administration of E. faecium increased mRNA abundance of claudin- 1 in the ileum of sucking piglets. Claudin1, ZO-1 and occludin are the most important components in the structural and functional organization of epithelial tight junctions [46]. Hence, the increased expression of claudin-1 suggests the better intestinal barrier function in response to dietary supplementation of E. faecium. Supportively, data from IPEC-J2 cell line indicated that E. faecium was able to increase the transepithelial electrical resistance of enterocyte monolayer, thus strengthening the intestinal barrier against ETEC [47].

Immunologically, the increased plasma IL- $1 \beta$ concentration and blood lymphocyte count indicated the successful establishment of immune model following ETEC 
challenge. Immunocyte number and variation reflect the immunity or infection status, an increase in the count and percentage of lymphocytes indicate inflammation $[48,49]$. The increased percentage of lymphocytes in the blood has been shown in piglets with ETEC challenge [49]. In this study, however, we found oral administration of E. faecium did not markedly alter the percentage of lymphocytes in the ETEC-challenged piglets, indicating $E$. faecium may have an anti-inflammatory effect against ETEC. Similarly, Tian et al. reported that E. faecium could effectively inhibit intestinal inflammation caused by ETEC [47]. T lymphocytes are responsible for cell-mediated immunity, and it can be divided into subsets according to the presence of CD4 and CD8 proteins [50]. The main function of $\mathrm{CD} 4^{+} \mathrm{T}$ cells is to direct the immune response towards invading pathogens and tumorigenic cells, and to maintain immune homeostasis [51], while $\mathrm{CD}^{+} \mathrm{T}$ cells play a pivotal role in the control of viral infections and tumor cells, for antigen-specific responses against multifarious pathogens and vaccineinduced immunity [52]. Previous study has shown that early administration of the probiotic E. faecium can modulate the composition of blood lymphocyte populations in sucking piglets [53]. Our study demonstrated that piglets in the PRO-ETEC group had lower percentage of $\mathrm{CD}^{+} \mathrm{T}$ cells compared with piglets in the CONETEC group. Similarly, there was a suppressive effect of the probiotic E. faecium on the $\mathrm{CD} 8^{+} \mathrm{T}$ cells, associating with a remarkable decrease in the colonization of pathogenic bacteria $[16,54]$.

The intestine is the largest immunological organ in the body, and as such is the location for the majority of lymphocytes and immune effector cells with pattern-recognition receptors [55]. Toll-like receptors (TLRs) are typical pattern recognition receptors in mediating mucosal innate host defense to maintain mucosal and commensal homeostasis [56]. It is well documented that the diarrhea and impaired intestinal barrier integrity are often associated with the activation of innate immunity and inflammatory response, in which the TLR/MyD88/ NF- $\mathrm{KB}$ signal pathway are involved $[57,58]$. It has been reported that ETEC expressing K88 fimbriae mediated bacterial adherence to host cells, which would activate innate immune response by delivering microbial associated molecular pattern products, such as LPS or fimbriae-dependent signaling $\mathrm{K} 88$, involving TLRs as pattern recognition receptors [59]. In the present study, our data indicated that ETEC infection stimulated the mRNA abundances of TLR2 and NF-KB in the ileum of ETEC-challenged piglets, which were significantly downregulated by the oral administration of E. faecium. Similarly, a previous study also showed that dietary supplementation of Lactobacillus acidophilus could alleviate the inflammatory response by inhibiting ETEC-induced
TLR2 expression, associating with the down-regulated NF- $\mathrm{BB}$ and MAPK signaling pathways in piglets [60]. Besides, the activated TLRs would stimulate the NF- $\mathrm{kB}$ signal pathway and then increase the expression of various inflammatory cytokines, including IL- $1 \beta$, TNF- $\alpha$ and IL6 , etc. $[60,61]$. In the present study, we found that ETEC challenge increased the level of TNF- $\alpha$ in the ileal mucosa. Importantly, piglets in the PRO+ETEC group normalized the concentration of TNF- $\alpha$ to be similar to those piglets in the PRO-ETEC group. Considering the crucial role of cytokines in immune and inflammatory responses [62], these findings indicate that oral administration of $E$. faecium may have beneficial effects in reducing intestinal inflammation in ETEC-challenged piglets.

The relationship between the gut microbiota and animal health is being extensively investigated. Intestinal microorganisms play critical roles in the development of host immune system [63]. During the early neonatal period, gut microbiota is unstable and prone to be modified $[64,65]$. Therefore, E. faecium administration to neonatal piglets may modify the composition of the gut microbiota for intestinal health. In this study, E. faecium administration and ETEC challenge did not affect the microbiota richness and diversity of suckling piglets. At the phylum level, however, the abundance of Proteobacteria tended to increase in piglets with ETEC challenge, and E. faecium supplementation significantly increased the abundance of Verrucomicrobia. Proteobacteria contains many enteric pathogens, such as Salmonella and Escherichia, which might cause diarrhea [19]. An increased prevalence of the phylum Proteobacteria in the gut reflects dysbiosis or unstable gut microbial community structure [66]. At the genus level, ETEC infection increased the abundance of Escherichia-Shigella in ETEC-challenged piglets. In contrast, a high abundance of Verrucomicrobia has been proposed as a hallmark of healthy gut due to its benefits on anti-inflammation and intestinal barrier function [67]. In this study, the increased abundance of Verrucomicrobia by E. faecium favor the colonic barrier function.

At the genus level, furthermore, piglets in the PROETEC group had lower abundance of Bilophila compared with piglets in the CON-ETEC group. A previous study has indicated that Bilophila is detected as a high abundant microbe in pathological conditions such as colitis and other intestinal inflammatory disorders [68]. The potential mechanism Bilophila causing intestinal inflammation is the production of sulfide that breaks the mucus barrier, thereby allowing close proximity of bacteria to the epithelium with epithelial damage and inflammation [69]. In our study, moreover, we found that piglets in the PRO+ETEC group normalized the relative abundance of Lachnoclostridium to be similar to those piglets in the PRO-ETEC group. Although Lachnoclostridium is responsible for 
SCFAs production [70], no significant differences were observed for the SCFAs contents in the digesta of the colon among groups. In addition, oral administration of E. faecium tended to decrease the abundance of Parabacteroides, which was taken as opportunistic pathogens in infectious diseases, and are able to develop antimicrobial drug resistance [71]. Parabacteroides spp. had a negative correlation with colonic expression of tight junction protein and anti-inflammatory protein genes [72]. This was consistent with our study that E. faecium administration improved the intestinal barrier function and immune function. The collective data described above suggest that oral administration of $E$. faecium could manipulate the microbiota profile with a decrease in pathogenic bacteria and an increase in beneficial bacteria, supporting the phenotype of intestinal health.

\section{Conclusion}

Our results indicate that oral administration of $E$. faecium to neonatal piglets had no significant effect on growth performance, but relieved the negative effects of ETEC infection on diarrhea, intestinal morphology and immunology of piglets, which could be partly ascribed to the changes in the intestinal microbiota profile.

\section{Additional file}

Additional file 1: Table S1. Effect of E. faecium on alpha diversity of microbial community in colonic content of piglets challenged with ETEC K88. Table S2. Effect of E. faecium on the relative abundance for the top 30 most abundant genera in the colon of piglets challenged with ETEC K88. Table S3. Effect of $E$. faecium on short chain fatty acid concentrations of piglets challenged with ETEC K88. Figure S1. The experimental design of the different treatments and procedures. Figure S2. Comparison of the gut microbiota composition among four groups. Principal coordinate analysis to visualize the unweighted UniFrac distances of colon digesta samples from individual piglet. (DOCX $137 \mathrm{~kb}$ )

\section{Abbreviations}

ADG: Average daily gain; BW: Body weight; CON: Control group; ETEC: Enterotoxigenic Escherichia coli; IL: Interleukin; MyD88: Myeloid differentiation factor 88; NF-kB: Nuclear transcription factor kappa B; PRO: Enterococcus faecium-supplemented group; TLR: Toll-like receptor; TRAF6: TNF receptor-associated factor 6; VCR: The ratio of villous height:crypt depth; ZO-1: Zonula occludens-1

\section{Acknowledgements}

We would like to thank the staff at our laboratory for their ongoing assistance.

\section{Consent to publication}

Not applicable.

\section{Authors' contributions}

$X P, R W$, and LC designed the experiments. XP, RW, LH, QZ, and $Y L$ performed the experiments. ZF, YL, SX, BF, JL, XJ, HL, DW, and $Y Z$ analyzed the experimental data. XP and LC wrote this paper. All authors read and approved the final manuscript.

\section{Funding}

This work was supported by the Projects of The National Key Research and Development Program of China (grant number 2016YFD0501204); Sichuan provincial project on S\&T application and demonstration (grant number 2016CC0070) and the project on commercialization of research findings under funding of government of Sichuan province (grant number 16ZHSF0385).

\section{Availability of data and materials}

The datasets analyzed in the current study are available from the corresponding author on reasonable request.

\section{Ethics approval and consent to participate}

All institutional and national guidelines for the care and use of laboratory animals were followed. The experimental procedures were approved by the Animal Care and Use Committee of Sichuan Agricultural University.

\section{Competing interests}

The authors declare that they have no competing interests.

\section{Author details}

${ }^{1}$ Key Laboratory for Animal Disease-Resistant Nutrition of the Ministry of Education of China, Institute of Animal Nutrition, Sichuan Agricultural University, Chengdu, Sichuan 611130, People's Republic of China. ${ }^{2}$ Animal Husbandry and Veterinary Department, Chengdu Agricultural College, Chengdu, Sichuan 611130, People's Republic of China.

Received: 20 February 2019 Accepted: 9 July 2019

Published online: 21 August 2019

\section{References}

1. Stokes CR, Bailey M, Haverson K, Harris C, Jones P, Inman C, et al. Postnatal development of intestinal immune system in piglets: implications for the process of weaning. Anim Res. 2004;53(4):325-34.

2. Gaskins HR, Croix JA, Nakamura N, Nava GM. Impact of the intestinal microbiota on the development of mucosal defense. Clin Infect Dis. 2008; 46(Supplement_2):S80-6.

3. Mackie RI, Sghir A, Gaskins HR. Developmental microbial ecology of the neonatal gastrointestinal tract. Am J Clin Nutr. 1999;69(5):1035s-45s.

4. Fanaro $S$, Chierici $R$, Guerrini $P$, Vigi V. Intestinal microflora in early infancy: composition and development. Acta Paediatr. 2003;92:48-55.

5. Foxxorenstein AE, Chey WD. Manipulation of the gut microbiota as a novel treatment strategy for gastrointestinal disorders. Am J Gastroenterol Suppl. 2012;1(1):41-6.

6. Rakoff-Nahoum S, Medzhitov R. Innate immune recognition of the indigenous microbial flora. Mucosal Immunol. 2008;1(1s):S10.

7. Rauch M, Lynch S. Probiotic manipulation of the gastrointestinal microbiota. Gut Microbes. 2010;1(5):335-8.

8. Konstantinov SR, Awati AA, Williams BA, Miller BG, Jones P, Stokes CR, et al. Post-natal development of the porcine microbiota composition and activities. Environ Microbiol. 2006;8(7):1191-9.

9. Fairbrother JM, Nadeau É, Gyles CL. Escherichia coli in postweaning diarrhea in pigs: an update on bacterial types, pathogenesis, and prevention strategies. Anim Health Res Rev. 2005;6(1):17-39.

10. Sayan H, Assavacheep P, Angkanaporn K, Assavacheep A. Effect of Lactobacillus salivarius on growth performance, diarrhea incidence, fecal bacterial population and intestinal morphology of suckling pigs challenged with F4+ enterotoxigenic Escherichia coli. Asian-Aust J Anim Sci. 2018;31(8):1308.

11. Chandler D, Mynott T. Bromelain protects piglets from diarrhoea caused by oral challenge with K88 positive enterotoxigenic Escherichia coli. Gut. 1998; 43(2):196-202

12. Nagy B, Fekete PZ. Enterotoxigenic Escherichia coli in veterinary medicine. Int J Med Microbiol. 2005;295(6-7):443-54.

13. Büsing K, Zeyner A. Effects of oral Enterococcus faecium strain DSM 10663 NCIMB 10415 on diarrhoea patterns and performance of sucking piglets. Benef Microbes. 2014;6(1):41-4

14. Yang $K$, Jiang Z, Zheng C, Wang L, Yang X. Effect of Lactobacillus plantarum on diarrhea and intestinal barrier function of young piglets challenged with enterotoxigenic Escherichia coli K88. J Anim Sci. 2014;92(4):1496-503.

15. Liu C, Zhu Q, Chang J, Yin Q, Song A, Li Z, et al. Effects of Lactobacillus casei and Enterococcus faecalis on growth performance, immune function and gut microbiota of suckling piglets. Arch Anim Nutr. 2017;71(2):120-33. 
16. Pollmann M, Nordhoff M, Pospischil A, Tedin K, Wieler L. Effects of a probiotic strain of Enterococcus faecium on the rate of natural chlamydia infection in swine. Infect Immun. 2005;73(7):4346-53.

17. Zeyner A, Boldt E. Effects of a probiotic Enterococcus faecium strain supplemented from birth to weaning on diarrhoea patterns and performance of piglets. J Anim Physiol Anim Nutr. 2006;90(1-2):25-31.

18. Mallo J, Riopérez J, Honrubia P. The addition of Enterococcus faecium to diet improves piglet's intestinal microbiota and performance. Livest Sci. 2010; 133(1-3):176-8.

19. Wang $Y$, Du W, Fu A, Zhang $X$, Huang $Y$, Lee $K$, et al. Intestinal microbiota and oral administration of Enterococcus faecium associated with the growth performance of new-born piglets. Benef Microbes. 2016;7(4):529-38.

20. Lojanica M, Manojlović M, Jeremić D, Petronijević S. The effects of probiotic Enterococcus faecium DSM 7134 in the weaned pigs nutrition. Biotechnol Anim Husbandry. 2010;26(1-2):57-64.

21. Huang Y, Li Y, Huang Q, Cui Z, Yu D, Rajput IR, et al. Effect of orally administered Enterococcus faecium EF1 on intestinal cytokines and chemokines production of suckling piglets. Pak Vet J. 2012;32:81-4.

22. Li W, Huang Y, Li Y, Huang Q, Cui Z, Yu D, et al. Effect of oral administration of Enterococcus faecium Ef1 on innate immunity of sucking piglets. Pak Vet J. 2012;33:9-13.

23. Slanetz L, Bartley $\mathrm{CH}$. Numbers of enterococci in water, sewage, and feces determined by the membrane filter technique with an improved medium. J Bacteriol. 1957;74(5):591-5.

24. Liu J, Yan H, Cao S, Liu J, Li Z, Zhang H. The response of performance in grower and finisher pigs to diets formulated to different tryptophan to lysine ratios. Livest Sci. 2019;222:25-30.

25. Liu J, Yan H, Zhang Y, Hu Y, Zhang H. Effects of dietary energy and protein content and lipid source on growth performance and carcass traits in Peking ducks. Poult Sci. 2019. https://doi.org/10.3382/ps/pez217

26. Sherman D, Acres S, Sadowski P, Springer J, Bray B, Raybould T, et al. Protection of calves against fatal enteric colibacillosis by orally administered Escherichia coli K99-specific monoclonal antibody. Infect Immun. 1983:42(2):653-8.

27. Che L, Xu Q, Wu C, Luo Y, Huang X, Zhang B, et al. Effects of dietary live yeast supplementation on growth performance, diarrhoea severity, intestinal permeability and immunological parameters of weaned piglets challenged with enterotoxigenic Escherichia coli K88. Br J Nutr. 2017:118(11):949-58.

28. Liu J, Xue P, Cao S, Liu J, Chen L, Zhang H. Effects of dietary phosphorus concentration and body weight on postileal phosphorus digestion in pigs. Anim Feed Sci Tech. 2019;242:86-94.

29. Han F, Hu L, Xuan Y, Ding X, Luo Y, Bai S, et al. Effects of high nutrient intake on the growth performance, intestinal morphology and immune function of neonatal intra-uterine growth-retarded pigs. Br J Nutr. 2013: 110(10):1819-27.

30. Hu L, Liu Y, Yan C, Peng X, Xu Q, Xuan Y, et al. Postnatal nutritional restriction affects growth and immune function of piglets with intra-uterine growth restriction. Br J Nutr. 2015;114(1):53.

31. Liu J, Zhang Y, Li Y, Yan H, Zhang H. L-tryptophan enhances intestinal integrity in diquat-challenged piglets associated with improvement of redox status and mitochondrial function. Animals. 2019:9:266.

32. Livak KJ, Schmittgen TD. Analysis of relative gene expression data using real-time quantitative PCR and the 2(-Delta Delta C(T)) method. Methods. 2001;25(4):402-8

33. Yan $H$, Zhang L, Guo Z, Zhang H, Liu J. Production phase affects the bioaerosol microbial composition and functional potential in swine confinement buildings. Animals. 2019;9:90.

34. Chen H, Mao X, He J, Yu B, Huang Z, Yu J, et al. Dietary fibre affects intestinal mucosal barrier function and regulates intestinal bacteria in weaning piglets. Br J Nutr. 2013;110(10):1837-48.

35. Yan H, Cao S, Li Y, Zhang H, Liu J. Reduced meal frequency alleviates highfat diet-induced lipid accumulation and inflammation in adipose tissue of pigs under the circumstance of fixed feed allowance. Eur J Nutr. 2019 https://doi.org/10.1007/s00394-019-01928-3.

36. Wunderlich PF, Braun L, Fumagalli I, D'Apuzzo V, Heim F, Karly M, et al. Double-blind report on the efficacy of lactic acid-producing Enterococcus SF68 in the prevention of antibiotic-associated diarrhoea and in the treatment of acute diarrhoea. J Int Med Res. 1989;17(4):333-8.

37. Bellomo G, Mangiagle A, Nicastro L, Frigerio G. A controlled double-blind study of SF68 strain as a new biological preparation for the treatment of diarrhoea in pediatrics. Curr Ther Res. 1980;28(6):927-36.
38. Xie Y, Zhang C, Wang L, Shang Q, Zhang G, Yang W. Effects of dietary supplementation of Enterococcus faecium on growth performance, intestinal morphology, and selected microbial populations of piglets. Livest Sci. 2018; 210:111-7.

39. Broom L, Miller H, Kerr K, Knapp J. Effects of zinc oxide and Enterococcus faecium SF68 dietary supplementation on the performance, intestinal microbiota and immune status of weaned piglets. Res Vet Sci. 2006;80(1):45-54

40. Martin L, Pieper R, Kröger S, Boroojeni FG, Vahjen W, Neumann K, et al. Influence of age and Enterococcus faecium NCIMB 10415 on development of small intestinal digestive physiology in piglets. Anim Feed Sci Technol. 2012;175(1-2):65-75.

41. Dibner J, Richards J. The digestive system: challenges and opportunities. J Appl Poult Res. 2004;13(1):86-93.

42. Xia MS, Hu CH, Xu ZR. Effects of copper bearing montmorillonite on the growth performance, intestinal microflora and morphology of weanling pigs. Anim Feed Sci Technol. 2005;118(3):307-17.

43. Pluske JR, Hampson DJ, Williams $I H$. Factors influencing the structure and function of the small intestine in the weaned pig: a review. Livest Sci. 1997; 51(1):215-36.

44. Turner JR. Molecular basis of epithelial barrier regulation: from basic mechanisms to clinical application. Am J Pathol. 2006;169(6):1901-9.

45. Piel C, Montagne L, Sève B, Lallès J-P. Increasing digesta viscosity using carboxymethylcellulose in weaned piglets stimulates ileal goblet cell numbers and maturation. J Nutr. 2005;135(1):86-91.

46. Suzuki T. Regulation of intestinal epithelial permeability by tight junctions. Cell Mol Life Sci. 2013;70(4):631-59.

47. Tian Z, Liu X, Dai R, Xiao Y, Wang X, Bi D, et al. Enterococcus faecium HDRsEf1 protects the intestinal epithelium and attenuates ETEC-induced IL-8 secretion in enterocytes. Mediat Inflamm. 2016;2016(5):1-10.

48. Demissie DE, Kaplan SL, Romero JR, Leake JA, Barson WJ, Halasa NB, et al. Altered neutrophil counts at diagnosis of invasive meningococcal infection in children. Pediatr Infect Dis J. 2013;32(10):1070-2.

49. Wu T, LV Y, Li X, Zhao D, Yi D, Wang L, et al. Establishment of a recombinant Escherichia coli-induced piglet diarrhea model. Front Biosci. 2018;23:1517-34.

50. Wang H, Ni X, Qing X, Liu L, Lai J, Khalique A, et al. Probiotic enhanced intestinal immunity in broilers against subclinical necrotic enteritis. Front Immunol. 2017:8:1592.

51. Wang Z, Shao Y, Guo Y, Yuan J. Enhancement of peripheral blood CD8+ $T$ cells and classical swine fever antibodies by dietary $\beta-1,3 / 1$, 6-glucan supplementation in weaned piglets. Transbound Emerg Dis. 2008;55(9-10):369-76.

52. Seder RA, Hill AV. Vaccines against intracellular infections requiring cellular immunity. Nature. 2000;406(6797):793.

53. Scharek-Tedin L, Filter M, Taras D, Wrede P, Schmidt MF. Influence of an Enterococcus faecium probiotic on the development of Peyer's patches B cells in piglets. Arch Anim Nutr. 2009;63(5):343-55

54. Scharek L, Guth J, Reiter K, Weyrauch K, Taras D, Schwerk P, et al. Influence of a probiotic Enterococcus faecium strain on development of the immune system of sows and piglets. Vet Immunol Immunop. 2005; 105(1-2):151-61.

55. Kelly D, Coutts A. Early nutrition and the development of immune function in the neonate. P Nutr Soc. 2000;59(2):177-85.

56. Villena J, Kitazawa H. Modulation of intestinal TLR4-inflammatory signaling pathways by probiotic microorganisms: lessons learned from Lactobacillus jensenii TL2937. Front Immunol. 2014;4(4):512.

57. Duan D, Zhang S, Li X, Guo H, Chen M, Zhang Y, et al. Activation of the TLR/MyD88/NF-KB signal pathway contributes to changes in IL-4 and IL-12 production in piglet lymphocytes infected with porcine circovirus type 2 in vitro. PLoS One. 2014;9(5):e97653.

58. Kawai T, Akira S. The roles of TLRs, RLRs and NLRs in pathogen recognition. Int Immunol. 2009;21(4):317-37.

59. Kaisho T, Akira S. Toll-like receptor function and signaling. J Allergy Clin Immun. 2006;117(5):979-87.

60. Li H, Zhang L, Chen L, Zhu Q, Wang W, Qiao J. Lactobacillus acidophilus alleviates the inflammatory response to enterotoxigenic Escherichia coli K88 via inhibition of the NF-KB and p38 mitogen-activated protein kinase signaling pathways in piglets. BMC Microbiol. 2016;16(1):273.

61. Li Q Verma I. NF-kappaB regulation in the immune system. Nat Rev Immunol. 2002;2(10):725-34. 
62. Praveena PE, Periasamy S, Kumar A, Singh N. Cytokine profiles, apoptosis and pathology of experimental Pasteurella multocida serotype A1 infection in mice. Res Vet Sci. 2010;89(3):332-9.

63. Toki S, Kagaya S, Shinohara M, Wakiguchi H, Matsumoto T, Takahata Y, et al. Lactobacillus rhamnosus GG and Lactobacillus casei suppress Escherichia coliinduced chemokine expression in intestinal epithelial cells. Int Arch Allergy Immunol. 2009;148(1):45-58.

64. Thompson CL, Wang B, Holmes AJ. The immediate environment during postnatal development has long-term impact on gut community structure in pigs. ISME J. 2008;2(7):739.

65. Hou C, Liu H, Zhang J, Zhang S, Yang F, Zeng X, et al. Intestinal microbiota succession and immunomodulatory consequences after introduction of Lactobacillus reuteri 15007 in neonatal piglets. PLoS One. 2015;10(3): e0119505.

66. Shin N-R, Whon TW, Bae J-W. Proteobacteria: microbial signature of dysbiosis in gut microbiota. Trends Biotechnol. 2015;33(9):496-503.

67. Fujio-Vejar $S$, Vasquez $Y$, Morales $P$, Magne F, Vera-Wolf $P$, Ugalde JA, et al. The gut microbiota of healthy chilean subjects reveals a high abundance of the phylum verrucomicrobia. Front Microbiol. 2017;8:1221.

68. Devkota S, Chang EB. Interactions between diet, bile acid metabolism, gut microbiota, and inflammatory bowel diseases. Dig Dis. 2015;33(3):351-6.

69. Ijssennagger $\mathrm{N}$, van der Meer R, van Mil SW. Sulfide as a mucus barrierbreaker in inflammatory bowel disease? Trends Mol Med. 2016;22(3):190-9.

70. Zeng H, Ishaq SL, Liu Z, Bukowski MR. Colonic aberrant crypt formation accompanies an increase of opportunistic pathogenic bacteria in C57BL/6 mice fed a high-fat diet. J Nutr Biochem. 2017:54:18-27.

71. Boente RF, Ferreira LQ, Falcão LS, Miranda KR, Guimarães PL, Santos-Filho J, et al. Detection of resistance genes and susceptibility patterns in Bacteroides and Parabacteroides strains. Anaerobe. 2010;16(3):190-4.

72. Lee S-M, Han HW, Yim SY. Beneficial effects of soy milk and fiber on high cholesterol diet-induced alteration of gut microbiota and inflammatory gene expression in rats. Food Funct. 2015;6(2):492-500.

Ready to submit your research? Choose BMC and benefit from:

- fast, convenient online submission

- thorough peer review by experienced researchers in your field

- rapid publication on acceptance

- support for research data, including large and complex data types

- gold Open Access which fosters wider collaboration and increased citations

- maximum visibility for your research: over $100 \mathrm{M}$ website views per year

At $\mathrm{BMC}$, research is always in progress.

Learn more biomedcentral.com/submissions 